\title{
Erratum
}

\section{A new collection of clay mineral 'Crystallinity' Index Standards and revised guidelines for the calibration of Kübler and Árkai indices - ERRATUM}

\section{Laurence N. Warr}

doi:10.1180/clm.2018.42, Published by Cambridge University Press, 17 December 2018.

(Version of Record published online: 14 March 2019)

The publisher apologises for the omission of a Reference from the Reference list on page 349. That Reference is given below:

Schomberg A., Wemmer K., Warr L.N. \& Grathoff G. (2019) $\mathrm{K}-\mathrm{Ar}$ age determinations on the fine fractions of 'Crystallinity Index Standards' from the Palaeozoic mudrocks of southwest

\section{Reference}

Warr L.N. (2018) A new collection of clay mineral 'Crystallinity' Index Standards and revised guidelines for the calibration of Kübler and Árkai indices. Clay Minerals. Published by Cambridge University Press, 17 December 2018. doi:10.1180/clm.2018.42 